\title{
Service Life Prediction of Electrolytic Capacitors in Urban Rail Transit Based on Analytical Iteration and $\mathbf{G M}(2,1)$ Model
}

\author{
Lei Wang, Lijun Diao, Ruichang Qiu, Chunmei Xu, and Peizhen Wang \\ School of Electrical Engineering, Beijing Jiaotong University, Beijing 100044, China \\ Correspondence should be addressed to Lijun Diao; ljdiao@bjtu.edu.cn
}

Received 16 August 2016; Revised 10 November 2016; Accepted 22 November 2016; Published 4 January 2017

Academic Editor: Ibrahim Zeid

Copyright (C) 2017 Lei Wang et al. This is an open access article distributed under the Creative Commons Attribution License, which permits unrestricted use, distribution, and reproduction in any medium, provided the original work is properly cited.

\begin{abstract}
In the power supply of urban rail transit system, electrolytic capacitors are used in large numbers. They suffer from inevitable ripple currents; such ripple currents generate heat dissipation, which shortens their service life seriously. To increase the reliability of the whole power supply system, the aging process of electrolytic capacitors must be evaluated, so that their service life could be predicted and measures could be taken in advance before their failures. When they are applied into the power supply system, the accuracy of conventional approaches is somewhat lowered, owing to the existence of unpredictable ripple current and ambient temperature variations. In this paper, we build an analytical ripple model to offer online aging monitoring of electrolytic capacitors. After that, a $\operatorname{GM}(2,1)$ model is adopted to predict service life with higher accuracy than conventional approaches.
\end{abstract}

\section{Introduction}

In the power supply of urban rail transit, the application of 4quadrant PWM converter (4QC) converts the braking energy from trains into the AC grid $[1,2]$. As is shown in Figure 1, capacitors are settled across the DC bus of $4 \mathrm{QC}$ to stabilize voltage. Conventional electrolytic capacitor is still massively chosen, because it shows larger capacitance in the same volume and it costs much less when it is compared with novel film capacitor. However, such electrolytic capacitor is fragile to external factors (ripple current, ambient temperature, etc.) [3], and its service life fluctuates seriously along with the variation of these external factors.

The power supply of urban rail transit consists of many electrical components, and the breaking of any single one of them would affect the whole system. The requirement for electrical component reliability in urban rail transit is much higher compared to most other power-electrical systems. Typically, an electrical component in urban rail transit is expected not to be broken in 30 years, which is scarcely possible in the case of electrolytic capacitor [4-6]. Electrolytic capacitors have made themselves the weak link of the whole system. In order to maintain or change electrolytic capacitors before they are broken, the online life prediction of them is indispensable [7]. Before life prediction, capacitor state should be evaluated in the first place, the result from which illustrates the current aging level of capacitor. The service life could be predicted after that, considering both the history variation trend and the current value of damage level.

Several literatures have done certain work in the aspect of electrolytic capacitor state evaluation, such as those ideas summarized in [8]. Reference [8] also states the shortcomings of the former references. What is more, in [9], ESR (Equivalent Serial Resistance) is derived based on the electrolyte volume that is left inside a capacitor. The decreasing rate of electrolyte is calculated with iteration, considering the affects from temperature rise, from structural layout of the capacitor, from vapor pressure inside the capacitor, and so forth. During the iteration, several coefficients are needed, which are fitted with data from different independent experiments. The problem lies in that the mutual coupling relationship among these coefficients is not taken into consideration in every specific experiment. What is more, average capacitor temperature is calculated to get the temperature rise, while core temperature should be considered here instead. The proposed approach is effective only in steady operating state of capacitor performance and could not be applied into dynamic operating state where the ripple current or ambient temperature changes 


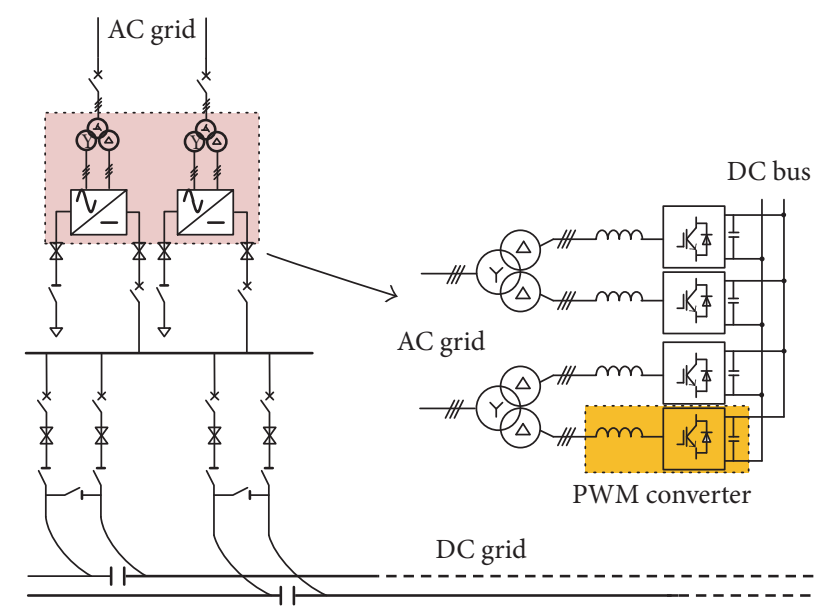

FIgURE 1: Power supply system in urban rail transit equipped with bidirectional 4-quadrant PWM converters.

inevitably; in [10], ESR is derived with dividing the voltage ripple that exists across capacitor by the ripple current that flows through the capacitor. In actual field application, the detection of ripple current is very difficult, and the additional current sensor could not be settled easily, which is necessary to detect ripple current. The settling difficulty originates mainly from the application of low-inductance bus bar, especially in high-voltage and high-power occasions; in [11], ESR is derived by a procedure which is similar to [9], and the change of ESR is also calculated by iteration to improve the accuracy. However, the effect from ambient temperature is not clearly taken into consideration during the iteration; hence its accuracy varies along with ambient temperature. What is more, the iteration with nonelectrical quantities somehow limits the accuracy, because most of them could not be detected easily online; other proposed approaches require additional signals [12] or circuit layouts [13, 14], and these approaches have found themselves in trouble, when they are applied into high-voltage and high-power electrical systems. Recently, artificial neutral network has been adopted into condition monitoring of electrolytic capacitors [15]. However, the training samples are hard to be derived in the case of power supply of urban rain transit, because of the randomness of the passenger flow. An ANN is liable to fall into local minimum, which also puts such procedure in dilemma. The method of Adaptive Neurofuzzy Inference System (ANFIS) algorithm shows similar problem [16]. Other approaches require high data processing capability of the system $[17,18]$, which makes them impossible to be embedded into existing control system of a $4 \mathrm{QC}$. This means more cost and extra maintenance procedures of the additional processing board for condition monitoring.

Moreover, the approaches that have been proposed before aim mainly at judging whether the capacitor is sound or not, instead of judging how much longer it could be used. Such problem limits their application effects in the first place, since that service life prediction is the destiny of state evaluation. More work should be done.
As a matter of fact, the ripple current and the ripple voltage across an electrolytic capacitor are unpredictable; they vary with external working conditions and can only be observed. However, the ESR or capacitance shift, which is calculated according to such observation, could reflect the present degrading situation of the capacitor. Then the changing characteristic of history degrading situation could be used as reference in the prediction procedure.

This paper offers a novel approach to the service life prediction of electrolytic capacitor. Likewise, the prediction is carried out based on state evaluation results. During the state evaluation, a novel iterative ripple model is chosen and carried out with detectable electrical quantities. The detection of such quantities calls for no additional sensors, because these quantities are also used by the existing control system of our $4 \mathrm{QC}$ for performance control. Under fluctuating device operating conditions and ambient temperatures, such iteration algorithm offers relatively higher accuracy and could be applied to high-voltage and high-power electrical systems while no additional signals or main circuit layouts are needed. The prediction process is carried out with a $\operatorname{GM}(2,1)$ grey model, which shows better accuracy in the presence of uncertainty and external variations. In the following part, the proposed approach will be explained thoroughly.

\section{The Degrading Signatures of Electrolytic Capacitor}

In the power supply of urban rain transit, the outgoing or incoming periodical DC current load of 4QC comes from a train of traction or braking, respectively. At the same time, the 4QC also sustains unpredictable DC current load because of the sudden change of external conditions (AC grid voltage variation, fan failure, etc.). Both the predictable periodical and the unpredictable occasional DC current load generate ripple currents in the DC side capacitors inevitably. Ripple currents would generate heat under the existence of ESR in the capacitor, and the heat leads to predictable periodical electrolyte loss or unpredictable occasional electrolyte loss. Electrolyte loss means fatigue, so damage accumulates simultaneously inside the electrolytic capacitor along with the 4QC operation.

Given that there are $N$ paralleled capacitor branches across the DC side of a 4QC $[1,2]$, the ripple current that flows through each capacitor branch is given in [19]

$$
I_{\text {rip }}=\frac{\sqrt{3} \cdot u_{\mathrm{ac}} \cdot I_{a} / U_{\mathrm{dc}}}{N} .
$$

In (1), $I_{\text {rip }}$ is the RMS (Root-Mean-Square) value of ripple current flowing through the $4 \mathrm{QC}$ capacitor branch, $u_{\mathrm{ac}}$ is the RMS value of $4 \mathrm{QC}$ AC voltage input, $I_{a}$ is the RMS value of AC current input, and $U_{\mathrm{dc}}$ is the mean value of the DC voltage output.

For the capacitor that we choose (model number is CD137, with the capacitance of $18000 \mu \mathrm{F}$ and the rated RMS ripple current of $47 \mathrm{~A}$ ), the ripple current rating of electrolytic capacitor is defined under $120 \mathrm{~Hz}$. Therefore, the ripple currents under other frequencies should be converted into that. Such 
TABLE 1: Conversion coefficient for CD137.

\begin{tabular}{lccccc}
\hline Frequency & 50,60 & 120 & 300 & $1 \mathrm{~K}$ & $\geq 10 \mathrm{k}$ \\
\hline$K_{\text {rip }}$ & 0.8 & 1.0 & 1.1 & 1.3 & 1.4 \\
\hline
\end{tabular}

conversion could be realized according to (2), where $K_{\text {rip }}$ is conversion coefficient (usually provided by the manufacturer). In (2), the value of $K_{\text {rip }}$ is given in Table 1. $I_{\text {rip }}$ and $I_{\text {rip }}^{\prime}$ are the ripple current before and after conversion:

$$
I_{\text {rip }}^{\prime}=K_{\text {rip }} \cdot I_{\text {rip }} \text {. }
$$

$I_{\text {rip }}^{\prime}$ and ESR generate heat inside the capacitor, and such heat results in core temperature rise $\Delta T$, as is given in

$$
\Delta T=\left(I_{\text {rip }}^{\prime}\right)^{2} \cdot \mathrm{ESR} \cdot R_{\mathrm{th} \Sigma} .
$$

In (3), $\left(I_{\text {rip }}^{\prime}\right)^{2} \cdot$ ESR is thermal power of the heat and $R_{\mathrm{th} \Sigma}$ is equivalent total thermal resistance of the capacitor. It should be known that temperature rise $\Delta T$ increases ESR, too, as is shown in

$$
\mathrm{ESR}_{T}=\mathrm{ESR}_{T_{\text {base }}} \cdot e^{\left(T-T_{\text {base }}\right) / E} .
$$

In (4), $\mathrm{ESR}_{T_{\text {base }}}$ is the ESR under reference ambient temperature $T_{\text {base }}$ (of which the average is $55^{\circ} \mathrm{C}$, in the case of $4 \mathrm{QC}$ in urban rail transit), $\mathrm{ESR}_{T}$ is the ESR value under temperature $T$, and $E$ is temperature coefficient. For CD137 capacitor that we choose, a typical value of $E$ is $22.7 \mathrm{~K}^{-1}$.

It should be noted that the interaction between core temperature and ESR is not enough to explain the whole aging process of an electrolytic capacitor, while high temperature itself means high degrading rate of the inner material or dielectric of a capacitor, according to Arrhenius equation and material characteristics [3]. However, in most cases, ESR and capacitance act as degrading signatures, since their variations signify the aging process of an electrolytic capacitor with relatively more accuracy $[5,6]$.

It could be seen from (3) and (4) that the degrading process inside a capacitor is "accelerated" all the time. During the degrading process, electrolyte is lost continuously along with the increasing of ESR. For electrolytic capacitor, the relationship between ESR and electrolyte volume is given in

$$
\frac{\mathrm{ESR}_{t, T_{\text {base }}}}{\operatorname{ESR}_{0, T_{\text {base }}}}=\left(\frac{V_{0}}{V_{t}}\right)^{2} .
$$

In (5), $\mathrm{ESR}_{0, T_{\text {base }}}$ and $V_{0}$ are the initial value of ESR and electrolyte volume. $\mathrm{ESR}_{t, T_{\text {base }}}$ and $V_{t}$ are the value of ESR and electrolyte volume on certain time spot $t$. In most cases, $\mathrm{ESR}_{t, T_{\text {base }}}$ and $V_{t}$ are calculated rather than detected [9-12]. It should be noted that both $\mathrm{ESR}_{0, T_{\text {base }}}$ and $\mathrm{ESR}_{t, T_{\text {base }}}$ should be under the same temperature $T_{\text {base }}$. However, actual capacitor temperature $T$ is different from $T_{\text {base }}$, and therefore the actually detected $\mathrm{ESR}_{t, T}$ should be converted into $T_{\text {base }}$. The conversation could be implemented according to (4). After that, (5) is revised to

$$
\frac{\mathrm{ESR}_{t, T} / e^{\left(T-T_{\text {base }}\right) / E}}{\mathrm{ESR}_{0, T_{\text {base }}}}=\left(\frac{V_{0}}{V_{t}}\right)^{2}
$$

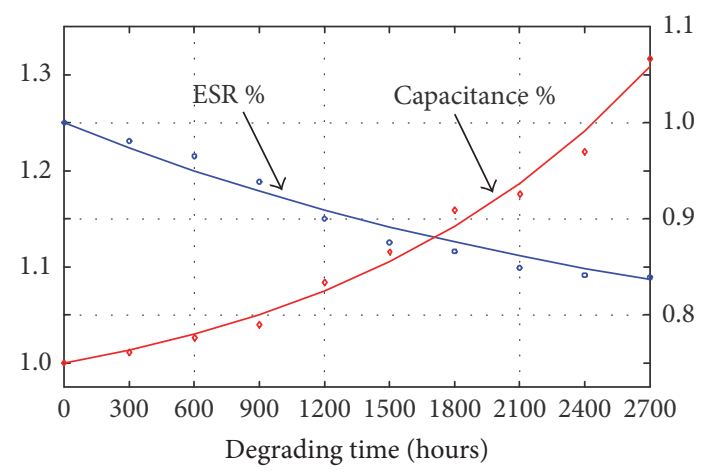

FIGURE 2: The experimental results from AGT (accelerated degrading test) on a CD137 electrolytic capacitor. $\diamond$ : the data derived in AGT. -: the fitted curve with LSM.

Equation (6) could be furtherly revised as (7), which shows the relationship between $V_{t}$ and $V_{0}$ :

$$
V_{t}=V_{0} \cdot \sqrt{\frac{\mathrm{ESR}_{0, T_{\text {base }}}}{\mathrm{ESR}_{t, T}} \cdot e^{\left(T-T_{\text {base }}\right) / E}} .
$$

Meanwhile, the capacitance of electrolytic capacitor changes inversely to electrolyte volume, which is shown in

$$
C_{t}=C_{0} \cdot \lambda_{1} \cdot \sqrt{\frac{\mathrm{ESR}_{t, T}}{\mathrm{ESR}_{0, T_{\text {base }}}} \cdot \frac{1}{e^{\left(T-T_{\text {base }}\right) / E}+\lambda_{2}}}
$$

In (8), $C_{0}$ is the initial capacitance, $C_{t}$ is the capacitance on time spot $t$, and $\lambda_{1}$ and $\lambda_{2}$ are correction coefficients. Based on (6) and (8), $\lambda_{1}$ and $\lambda_{2}$ could be obtained by means of Least Square Method (LSM) and could be calculated with the results from accelerated degrading test (AGT).

During AGT, an electrolytic capacitor operates under given ripple current while its ambient temperature is increased by external means, so that the degrading process is shortened greatly. Under the same ripple current, every temperature rise of $10^{\circ} \mathrm{C}$ would shorten the test time by about $50 \%$ [11]. Figure 2 shows the data we derived from an AGT with the CD137 capacitor. The AGT is carried out under constant RMS ripple current of $56 \mathrm{~A}$ and under the ambient temperature of $85^{\circ} \mathrm{C}$. During the AGT, $\mathrm{ESR}_{t, T}\left(T=85^{\circ} \mathrm{C}\right)$ and capacitance $C_{t}$ of the capacitor is detected at an interval of 300 hours. The ESR \% and capacitance \% in Figure 2 are calculated according to (9). In this case, $\lambda_{1}$ and $\lambda_{2}$ are calculated to be 0.954 and 0.027 , respectively:

$$
\begin{aligned}
\mathrm{ESR} \% & =\frac{\mathrm{ESR}_{t, T} / e^{\left(T-T_{\text {base }}\right) / E}}{\mathrm{ESR}_{0, T_{\text {base }}}}, \\
\text { Capacitance } \% & =\frac{C_{t}}{C_{0}} .
\end{aligned}
$$

The degrading of capacitor is a nonlinear process, and ESR and capacitance change in similar pattern simultaneously. They could be taken as the degrading signatures of electrolytic capacitor, and the online calculation of them is the purpose of state evaluation. 


\section{The Analytical Iterative Ripple Model for State Evaluation of Electrolytic Capacitor in 4QC}

During the state evaluation of electrolytic capacitor, ESR and capacitance are often calculated instead of being detected [914]. In most cases, the calculation is carried out by means of iteration with nonelectrical quantities, such as capacitor temperature, vapor pressure inside, and the electrolyte left [9, 11]. However, the iteration approach that we propose in this paper is carried out with electrical quantities instead of with conventional nonelectrical quantities. Since these electrical quantities are more likely to be detectable with sufficient accuracy, the approach proposed shows some merits in practicability. These electrical quantities we need have already been used by the control of 4QC, so no additional transducers are required.

4QC shows different characteristics during different operating stages $[1,2]$, and the ripple current that flows through capacitor is different at the same time. Therefore, the iteration should be carried out with different ripple models, according to $4 \mathrm{QC}$ operating stage. In general, there are 2 different operating stages of $4 \mathrm{QC}$ :

(i) Before a 4QC is started, the capacitors on its DC side must be precharged. Such precharging stage eliminates the current surge of capacitors, which would exist if the $4 \mathrm{QC}$ is connected directly to AC grid. During the precharging stage, the $4 \mathrm{QC}$ works as a fullbridge rectifier.

(ii) When a train in urban transit is speeding up, the 4QC works as a rectifier, which converts the AC energy from AC grid into DC energy and supplies it to the train; when a train in urban transit is slowing down, the 4QC works as an inverter, which converts the DC energy from the train into $\mathrm{AC}$ energy and supplies it to AC grid. During such rectifying or inverting stage, the 4QC works as a current-controlled voltage source in essence.

In the following part, the ripple models are derived by analytical iteration with electrical currents and voltages, which are corresponding to these two operating stages.

3.1. The Ripple Model Corresponding to Precharging Stage of $4 Q C$. The equivalent topology of $4 \mathrm{QC}$ during precharging stage is shown in Figure 3. In Figure $3, i_{a \sim c}$ are AC grid current inputs, $L$ is the inductance of grid-side inductor, $R$ is grid-side parasitic resistance, $e_{a \sim c}$ are AC grid phase voltages, D1 6 are antiparallel diodes of power circuit IGBT modules, $C$ is the capacitance across DC bus, $i_{\text {ripple }}$ is the ripple current which flows through $C, S$ is the contactor between $4 \mathrm{QC}$ and its DC load, $U_{\mathrm{dc}}$ is the voltage on DC side, $i_{\mathrm{dc}}$ is the DC current load, and $R_{L}$ is equivalent resistance of the DC load. The current reference directions are represented by arrows in Figure 3.

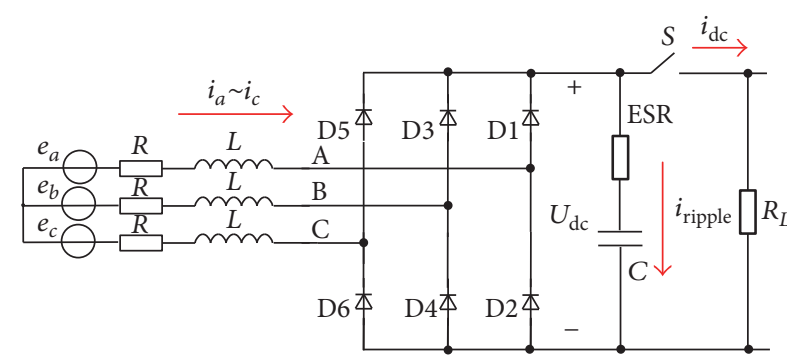

FIGURE 3: Equivalent topology of 4QC during precharging stage. law:

Equation (10) could be obtained, according to Kirchhoff's

$$
C \cdot \frac{d}{d t}\left(U_{\mathrm{dc}}-i_{\text {ripple }} \cdot \mathrm{ESR}\right)=\sum_{j=a \sim c} i_{j} .
$$

It should be noted that the sum of $i_{a \sim c}$ equals zero only when fundamental components of $i_{a \sim c}$ are considered. However, it is not zero constantly due to the existence of harmonic components in $i_{a \sim c}$. According to (10), $i_{\text {ripple }}$ could be derived from $i_{a \sim c}$ and $i_{\mathrm{dc}}$, if $C$ and ESR are given. After simplification and discretization, (10) could be revised as

$$
C \cdot \frac{\Delta U_{\mathrm{dc}}}{T_{s}}-\mathrm{ESR} \cdot C \cdot \frac{\Delta\left(\sum_{j=a \sim c} i_{j}\right)}{T_{s}}=\sum_{j=a \sim c} i_{j} .
$$

In (11), $T_{s}$ is the sampling interval of 1 millisecond (such interval is also used by existing 4QC control system). Since $i_{a \sim c}$ and $U_{\mathrm{dc}}$ are detectable with existing transducers, (11) shows a way to calculate capacitance and ESR by iteration, which is given thoroughly in (12).

In (12), $C_{k T_{s}}$ and $C_{(k-1) T_{s}}$ are the capacitance on time spots $k T_{s}$ and $(k-1) T_{s}$, respectively. $\operatorname{ESR}_{k T_{s}, T}$ is the ESR on $k T_{s}$ and, under ambient temperature $T, \mathrm{ESR}_{(k-1) T_{s}, T}$ is the ESR on $(k-$ 1) $T_{s}$ and under ambient temperature $T . U_{\mathrm{dc}}(k)$ and $U_{\mathrm{dc}}(k-1)$ are sampled on $k T_{s}$ and $(k-1) T_{s}$, which is also the case with $i_{a \sim c}$.

However, (12) is not sufficient to calculate two variables $\left(C_{k T_{s}}\right.$ and $\left.\mathrm{ESR}_{k T_{s}, T}\right)$ at the same time. By combining (12) with (8), the iterative solution of $C_{k T_{s}}$ and $\mathrm{ESR}_{k T_{s}, T}$ is finally derived in (13).

3.2. The Ripple Model Corresponding to Rectifying or Inverting Stage of $4 Q C$. Figure 4 shows the equivalent topology of 4QC during rectifying stage. The iterative ripple model could be derived in a similar way to precharging stage, while the equivalent equation according to Kirchhoff's Law is shown in (14).

Equation (14) could be revised as (15), and then the ripple model corresponding to rectifying stage is given in (16). $i_{\mathrm{dc}}$ here in (14) (16) is the DC current load of 4QC. It should be noted that (14) (16) also hold true during inverting stage, while $i_{\mathrm{dc}}$ is negative and the phases of $i_{a \sim c}$ are opposite in that case.

The 4QC control system implements capacitor state evaluation, by calculating ESR and $C$ online with (13) and 


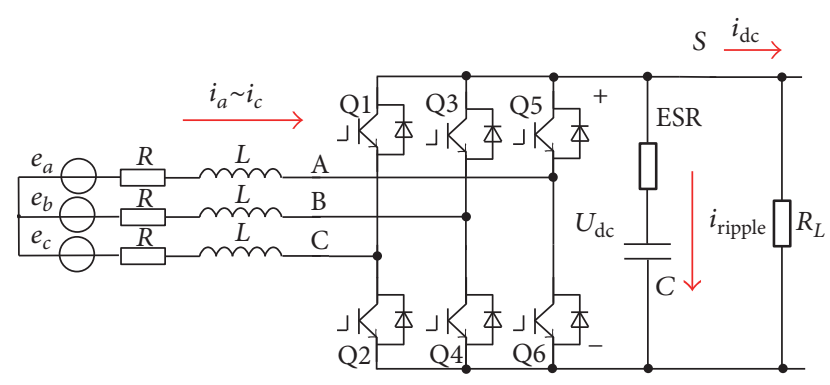

FIgURE 4: Equivalent topology of rectifying 4QC.

(16). However, state evaluation of capacitor is not our final purpose; it acts only as intermediate link to the prediction of service life. The current values of ESR and $C$ should be and could be further utilized in life prediction, together with the historical variation trend of them:

$$
\begin{gathered}
C_{k T_{s}} \cdot \frac{U_{C}(k)-U_{C}(k-1)}{T_{s}}-\operatorname{ESR}_{k T_{s}, T} \cdot C_{k T_{s}} \\
. \frac{\sum_{j=a \sim c} i_{j}(k)-\sum_{j=a \sim c} i_{j}(k-1)}{T_{s}}-\mathrm{ESR}_{k T_{s}, T} \cdot C_{k T_{s}} \\
. \frac{i_{\mathrm{dc}}(k)-i_{\mathrm{dc}}(k-1)}{T_{s}}=\sum_{j=a \sim c} i_{j}(k)+i_{\mathrm{dc}}(k), \\
C_{k T_{s}}=\left(\sum_{j=a \sim c} i_{j}(k)+i_{\mathrm{dc}}(k)+\left(\left(\sum_{j=a \sim c} i_{j}(k)+i_{\mathrm{dc}}(k)\right)^{2}\right.\right. \\
+4 \cdot \frac{U_{C}(k)-U_{C}(k-1)}{T_{s}} \\
. \frac{\sum_{j=a \sim c} i_{j}(k)-\sum_{j=a \sim c} i_{j}(k-1)+i_{\mathrm{dc}}(k)-i_{\mathrm{dc}}(k-1)}{T_{s}} \\
. \lambda_{1}^{2} \cdot C_{0}^{2} \cdot\left(\frac{\mathrm{ESR}_{(k-1) T_{s}, T}}{\mathrm{ESR}_{0, T_{\mathrm{base}}}} \cdot \frac{1}{\left.\left.\left.e^{\left(T-T_{\mathrm{base}}\right) / E}+\lambda_{2}\right)\right)^{1 / 2}\right)(2}\right)^{-1},
\end{gathered}
$$$$
\mathrm{ESR}_{k T_{s}, T}=\left(4 \lambda_{1}^{2} \cdot C_{0}^{2} \cdot\left(\frac{\mathrm{ESR}_{(k-1) T_{s}, T}}{\mathrm{ESR}_{0, T_{\text {base }}}} \cdot \frac{1}{e^{\left(T-T_{\text {base }}\right) / E}}+\lambda_{2}\right)\right.
$$$$
\left.\cdot\left[\frac{U_{C}(k)-U_{C}(k-1)}{T_{s}}\right]^{2}\right)\left(\sum_{j=a \sim c} i_{j}(k)+i_{\mathrm{dc}}(k)\right.
$$$$
+\left(\left(\sum_{j=a \sim c} i_{j}(k)+i_{\mathrm{dc}}(k)\right)^{2}+4 \cdot \frac{U_{\mathrm{C}}(k)-U_{\mathrm{C}}(k-1)}{T_{s}}\right.
$$

$$
\begin{aligned}
& \cdot \frac{\sum_{j=a \sim c} i_{j}(k)-\sum_{j=a \sim c} i_{j}(k-1)+i_{\mathrm{dc}}(k)-i_{\mathrm{dc}}(k-1)}{T_{s}} \\
& \left.\left.\cdot \lambda_{1}^{2} \cdot C_{0}^{2} \cdot\left(\frac{\operatorname{ESR}_{(k-1) T_{s}, T}}{\operatorname{ESR}_{0, T_{\text {base }}}} \cdot \frac{1}{e^{\left(T-T_{\text {base }}\right) / E}}+\lambda_{2}\right)\right)^{1 / 2}\right)^{-1}, \\
& C \cdot \frac{d}{d t}\left(U_{C}-i_{\text {ripple }} \cdot \mathrm{ESR}\right)=\sum_{j=a \sim c} i_{j}+i_{\mathrm{dc}} \\
& C_{k T_{s}} \cdot \frac{U_{C}(k)-U_{C}(k-1)}{T_{s}}-\mathrm{ESR}_{k T_{s}, T} \cdot C \\
& \frac{\sum_{j=a \sim c} i_{j}(k)-\sum_{j=a \sim c} i_{j}(k-1)}{T_{s}}-\mathrm{ESR}_{k T_{s}, T} \cdot C_{k T_{s}} \\
& \cdot \frac{i_{\mathrm{dc}}(k)-i_{\mathrm{dc}}(k-1)}{T_{\mathrm{s}}}=\sum_{j=a \sim c} i_{j}(k)+i_{\mathrm{dc}}(k), \\
& C_{k T_{s}}=\left(\sum_{j=a \sim c} i_{j}(k)+i_{\mathrm{dc}}(k)+\left(\left(\sum_{j=a \sim c} i_{j}(k)+i_{\mathrm{dc}}(k)\right)^{2}\right.\right. \\
& +4 \cdot \frac{U_{C}(k)-U_{C}(k-1)}{T_{s}} \\
& \cdot \frac{\sum_{j=a \sim c} i_{j}(k)-\sum_{j=a \sim c} i_{j}(k-1)+i_{\mathrm{dc}}(k)-i_{\mathrm{dc}}(k-1)}{T_{s}} \\
& \left.\left.\cdot \lambda_{1}^{2} \cdot C_{0}^{2} \cdot\left(\frac{\operatorname{ESR}_{(k-1) T_{s}, T}}{\operatorname{ESR}_{0, T_{\text {base }}}} \cdot \frac{1}{e^{\left(T-T_{\text {base }}\right) / E}}+\lambda_{2}\right)\right)^{1 / 2}\right)(2 \\
& \left.\frac{U_{C}(k)-U_{C}(k-1)}{T_{s}}\right)^{-1} \\
& \mathrm{ESR}_{k T_{s}, T}=\left(4 \lambda_{1}^{2} \cdot C_{0}^{2} \cdot\left(\frac{\mathrm{ESR}_{(k-1) T_{s}, T}}{\mathrm{ESR}_{0, T_{\text {base }}}} \cdot \frac{1}{e^{\left(T-T_{\text {base }}\right) / E}}+\lambda_{2}\right)\right. \\
& \left.\cdot\left[\frac{U_{\mathrm{C}}(k)-U_{\mathrm{C}}(k-1)}{T_{s}}\right]^{2}\right)\left(\sum_{j=a \sim c} i_{j}(k)+i_{\mathrm{dc}}(k)\right. \\
& +\left(\left(\sum_{j=a \sim c} i_{j}(k)+i_{\mathrm{dc}}(k)\right)^{2}+4\right. \\
& \frac{U_{C}(k)-U_{C}(k-1)}{T_{s}} \\
& \frac{\sum_{j=a \sim c} i_{j}(k)-\sum_{j=a \sim c} i_{j}(k-1)+i_{\mathrm{dc}}(k)-i_{\mathrm{dc}}(k-1)}{T_{s}} \\
& \left.\left.\cdot \lambda_{1}^{2} \cdot C_{0}^{2} \cdot\left(\frac{\operatorname{ESR}_{(k-1) T_{s}, T}}{\operatorname{ESR}_{0, T_{\text {base }}}} \cdot \frac{1}{e^{\left(T-T_{\text {base }}\right) / E}}+\lambda_{2}\right)\right)^{1 / 2}\right)^{-1} .
\end{aligned}
$$




\section{Life Prediction of Electrolytic Capacitor in the $4 Q \mathrm{C}$}

In classical life prediction procedures, damage is considered to accumulate in a linear way. An early example is the wellknown Miner's Criterion, which was introduced by Miner M. A. in 1945. Miner's Criterion solves the problem of mechanical degrading perfectly, but it finds itself in dilemma under electrical components degrading issues. Later on, Weibull Distribution is introduced to depict safety chain system [20], while it also fails to predict in dynamic state with sufficient accuracy. In electrolytic capacitor, both periodical and occasional damage lead to its degrading. Periodical damage prevails in steady state of capacitor, when external ripple current and ambient temperature stay the same. Weibull Distribution approximates such periodical degrading course excellently $[12,13]$. However, in dynamic state when occasional fluctuation exists, occasional damage makes the accumulation trend vary greatly. In this case, the grey model (GM) could do a better job, while Weibull Distribution no longer follows the trend with sufficient accuracy [21]. GM predicts better under small sample space and uncertainty, which is just our case $[1,2,22,23]$. As for $\operatorname{GM}, \operatorname{GM}(1,1)$ and $\operatorname{GM}(2,1)$ are two important branches [24-26]. They are both effective in short-term prediction, but $\operatorname{GM}(1,1)$ fails to achieve sufficient accuracy in long term prediction, especially under unpredictable load or ambient temperature variations. Therefore, $\operatorname{GM}(2,1)$ model is more suitable in our case.

Similar to conventional linear prediction approach, our prediction procedure also chooses damage degree (DD) to assess the degrading level. The DD on time spot $n T_{p}$ is represented with $D(n)$, while $T_{p}$ is the calculation interval during the prediction. $T_{p}$ is different from the former $T_{s} . T_{s}$ is shorter, so that ESR and capacitance are calculated with sufficient accuracy. $T_{p}$ should be longer than $T_{s}$, because the service life of capacitor is usually thousands of hours. In our work, $T_{p}$ is chosen to be 1 hour.

As is given in (17), $D(n)$ is calculated with capacitance, while $C(n)$ is the capacitance on time spot $n T_{p}$ and $C_{0}$ is the initial capacitance. It should be noted that, according to (6) and (8), the variations of ESR and $C$ are correlated. Such correlation could also be observed in Figure 2. Therefore, either ESR or capacitance depicts the whole degrading process effectively, while only capacitance is considered in

$$
D(n)=\frac{C_{0}-C(n)}{C_{0}} .
$$

For an electrolytic capacitor, $D(n)$ larger than certain threshold often means that the capacitor has come to an end. It should be noted that the damage degree threshold for an electrolytic capacitors should be chosen by considering the following facts:

(1) Being chosen according to the ESR or capacitance tolerance provided by manufacturers.

(2) Being chosen according to the allowable ESR or capacitance deviation determined by the equipment performance requirements, in which the capacitor is settled.
In the case of a CD137 capacitor, the threshold of 0.4 is chosen, according to data provided by its manufacturer [27]. The time spot $n T_{p}$, on which $D(n)$ is larger than 0.4 , could be deemed as the service life of a CD137 capacitor. By prediction of $D(n), n T_{p}$ could also be predicted simultaneously.

$\operatorname{GM}(2,1)$ model constructs a second-order differential equation, which describes the changing trend of the predicted quantity. The differential equation is shown in (18), while prediction is implemented with $D^{(1)}(t)$, and $\beta_{1} \sim \beta_{3}$ are coefficients to be determined with $\operatorname{GM}(2,1)$ algorithm.

$$
\frac{d^{2}}{d t^{2}} D^{(1)}(t)+\beta_{1} \frac{d}{d t} D^{(1)}(t)+\beta_{2} D^{(1)}(t)=\beta_{3}
$$

By $(18), D^{(1)}(t)$ could be solved to be

$$
\begin{aligned}
& D^{(1)}(t)=L^{-1}\left[\frac{\beta_{3}}{s\left(s^{2}+\beta_{1} s+\beta_{2}\right)}\right. \\
& \left.\quad+\frac{D^{(1)}\left(0_{-}\right) s+D^{(1)^{\prime}}\left(0_{-}\right)+\beta_{1} D^{(1)}\left(0_{-}\right)}{s^{2}+\beta_{1} s+\beta_{2}}\right] .
\end{aligned}
$$

The initial conditions of (19) are

$$
\begin{aligned}
D^{(1)}\left(0_{-}\right) & =\left.D^{(0)}(t)\right|_{t=0_{-}}=\left.D^{(0)}(k)\right|_{k=1}, \\
D^{(1)^{\prime}}\left(0_{-}\right) & \left.\approx D^{(1)}(t)\right|_{t=0_{+}}-\left.D^{(1)}(t)\right|_{t=0_{-}} \\
& =\left.D^{(0)}(k)\right|_{k=2} .
\end{aligned}
$$

Equation (18) takes an analogous form. However, digitalized system calls for difference equations instead of differential equations. In GM theory, (18) is actually equalized to be a difference equation in

$$
\begin{aligned}
& \sigma\left(D^{(0)}(n)\right)+\beta_{1} D^{(0)}(n-1) \\
& \quad+\beta_{2}\left[0.5 D^{(1)}(n-1)+0.5 D^{(1)}(n)\right]=\beta_{3} .
\end{aligned}
$$

In $(21), D^{(1)}(n)$ is the sum of $D^{(0)}(n)$, as is given in (22). $D^{(0)}(i)$ is equal to $D(i)$. The symbol of $\sigma$ means 1st-order difference

$$
D^{(1)}(n)=\sum_{i=0}^{n} D^{(0)}(i)
$$

Moreover, the coefficient vector $\left(\begin{array}{lll}\beta_{1} & \beta_{2} & \beta_{3}\end{array}\right)$ in equation (18) is derived by LSM algorithm with a pseudo inverse matrix $\left(A^{T} A\right)^{-1}$ :

$$
\left(\begin{array}{lll}
\beta_{1} & \beta_{2} & \beta_{3}
\end{array}\right)=\left(A^{T} A\right)^{-1} A^{T} B .
$$


In (23), the metrics of $A$ and $B$ are

A

$=\left(\begin{array}{ccc}-D^{(0)}(1) & -0.5 D^{(1)}(1)-0.5 D^{(1)}(2) & 1 \\ -D^{(0)}(2) & -0.5 D^{(1)}(2)-0.5 D^{(1)}(3) & 1 \\ \vdots & \vdots & \vdots \\ -D^{(0)}(n-1) & -0.5 D^{(1)}(n-1)-0.5 D^{(1)}(n) & 1\end{array}\right)$,

$B=\left(\begin{array}{c}\sigma\left(D^{(0)}(2)\right) \\ \sigma\left(D^{(0)}(3)\right) \\ \vdots \\ \sigma\left(D^{(0)}(n)\right)\end{array}\right)$.

Therefore, $D^{(1)}(n)$ could be derived as is shown in (25), which equals the sum of several residues:

$$
\begin{aligned}
& D^{(1)}(n)=\operatorname{Res}\left[\frac{\beta_{3}}{s\left(s^{2}+\beta_{1} s+\beta_{2}\right)} e^{s n T_{p}}, 0\right] \\
&+\operatorname{Res}\left[\frac{\beta_{3}}{s\left(s^{2}+\beta_{1} s+\beta_{2}\right)} e^{s n T_{p}}, \frac{-\beta_{1}-\sqrt{\beta_{1}^{2}-4 \beta_{2}}}{2}\right] \\
&+\operatorname{Res}\left[\frac{\beta_{3}}{s\left(s^{2}+\beta_{1} s+\beta_{2}\right)} e^{s n T_{p}}, \frac{-\beta_{1}+\sqrt{\beta_{1}^{2}-4 \beta_{2}}}{2}\right] \\
&+\operatorname{Res}\left[\frac{D^{(1)}\left(0_{-}\right) s}{s^{2}+\beta_{1} s+\beta_{2}} e^{s n T_{p}}, \frac{-\beta_{1}-\sqrt{\beta_{1}^{2}-4 \beta_{2}}}{2}\right] \\
&+\operatorname{Res}\left[\frac{D^{(1)}\left(0_{-}\right) s}{s^{2}+\beta_{1} s+\beta_{2}} e^{s n T_{p}}, \frac{-\beta_{1}+\sqrt{\beta_{1}^{2}-4 \beta_{2}}}{2}\right] .
\end{aligned}
$$

If current time spot is $n T_{p}$, then the damage degree on future time spot $(n+i) T_{p}$ could be calculated by

$$
\begin{array}{r}
D^{(0)}(n+i)=D^{(1)}(n+i)-D^{(1)}(n+i-1), \\
i=1,2,3, \ldots .
\end{array}
$$

Finally, the service life is derived according to

$$
L=j T_{p} \text {, when }\left|D^{(0)}(n+j)-0.4\right|<\zeta .
$$

In (27), it is assumed that the current time is $n T_{p} . L$ is the predicted service life, and $\zeta$ is the hysteresis error threshold. According to experimental results, $\zeta$ is chosen as $5 \times 10^{-5}$, so that the error gap of $L$ is $50 T_{p}$ while $T_{p}$ equals 1 hour.

\section{Actual Implementation of the Life Prediction Process}

Altogether, it takes the following steps to predict service life of electrolytic capacitor in 4QC:

(1) To detect $i_{a \sim c}$ for the sum of $i_{a \sim c}$ on time spots $k T_{s}$ and $(k-1) T_{s}$. To detect $i_{\mathrm{dc}}$ for $i_{\mathrm{dc}}(k)$ and $i_{\mathrm{dc}}(k-1)$.

(2) To detect ambient temperature $T$.

(3) To calculate $C_{k T_{s}}$ and $\operatorname{ESR}_{k T_{s}, T}$ according to (13) or (16), depending on $4 \mathrm{QC}$ operating stage.

(4) To sample the capacitance sequence of $C_{k T_{s}}, C_{(k-1) T_{s}}$, and $C_{(k-2) T_{s}}, \ldots, C_{0}$ for $C_{n T_{p}}$ and $C_{(n-1) T_{p}}, \ldots, C_{0}$.

(5) To calculate $D^{(0)}(n), D^{(0)}(n-1), \ldots, D^{(0)}(0)$ with $C_{n T_{p}}$ and $C_{(n-1) T_{p}}, \ldots, C_{0}$ according to (17).

(6) To calculate $D^{(1)}(n), D^{(1)}(n-1), \ldots, D^{(1)}(0)$ with $D^{(0)}(n), D^{(0)}(n-1), \ldots, D^{(0)}(0)$ according to $(22)$.

(7) To predict $D^{(1)}(n+i), D^{(1)}(n+i-1), \ldots, D^{(1)}(n+1)$, according to (25).

(8) To derive $D^{(0)}(n+i), D^{(0)}(n+i-1), \ldots, D^{(0)}(n+1)$, according to (26).

(9) To obtain the service life of electrolytic capacitor, according to (27).

In the following example, the DC side of $4 \mathrm{QC}$ contains 6 paralleled capacitor branches while each branch is made up of 4 capacitors in series. There are altogether 24 capacitors, each capacitor is CD137 (as is stated in Section 2) and the equivalent total capacitance is $27000 \mu \mathrm{F}$. The AC grid voltage of 4QC (in RMS and line-to-line) is $800 \mathrm{~V}$ and $U_{\mathrm{dc}}$ is $1650 \mathrm{~V}$. The capacity of $4 \mathrm{QC}$ is $1 \mathrm{MW}$. Typically, the service life of CD137 capacitor is around 10000 hours under rated ripple current (47 A in RMS) and ambient temperature $85^{\circ} \mathrm{C}$; however, its service life varies with actual ripple current and ambient temperature.

Figure 5 shows the calculated capacitance under different DC loads and ambient temperatures $\left(I_{\mathrm{dc}}\right.$ and $\left.T\right)$, and the calculation is carried out with our proposed iterative analytical ripple model. It should be noted that the calculated capacitance is divided by 10 so that all the curves could be drawn in the $Y$-axis range of $(-500,2000)$. In Figure 5, $I_{\mathrm{dc}}$ and $T$ change in 3 phases $\left(100 \mathrm{~A} / 45^{\circ} \mathrm{C}, 300 \mathrm{~A} / 65^{\circ} \mathrm{C}\right.$, and $500 \mathrm{~A} / 85^{\circ} \mathrm{C}$ ). It is obvious that the ripple current $I_{\text {rip }}^{\prime}$ increases with $I_{\mathrm{dc}}$ and $T$. In Figure 5, short-term fluctuation exists in $U_{\mathrm{dc}}$ during the transition between different stages, and such fluctuation comes from the closed loop regulation of 4QC under varying DC load $[1,2]$. Similar fluctuation also exists in ripple currents and the calculated capacitance. Such fluctuation produces damage degree error of about $3 \%$ and could be eliminated by filter with a time delay of $100 \mathrm{~ms}$. 


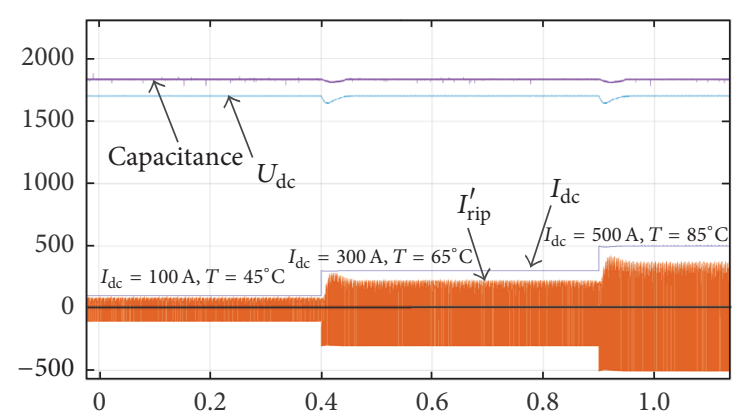

FIGURE 5: The iteration results of capacitance under different ripple currents and ambient temperatures.

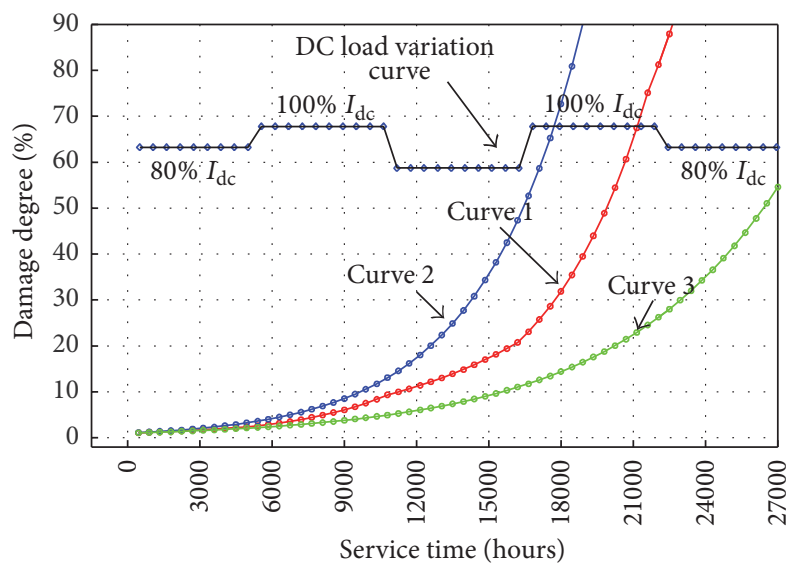

FIGURE 6: The degrading process of electrolytic capacitor with different load conditions.

Figure 5 means that the calculated capacitance is accurate under varying DC loads and ambient temperatures.

Figure 6 shows the degrading process of CD137 capacitor under different DC loads $\left(I_{\mathrm{dc}}\right)$ while ambient temperature $\left(T_{\text {base }}\right)$ stays on $55^{\circ} \mathrm{C}$. The degrading process is depicted by damage degree (DD), which is calculated according to (17). Curve 1 in Figure 6 shows the aging of capacitor with actual DC load variation (illustrated by horizontal lines in Figure 6), while curve 2 in Figure 6 shows the degrading process under constant $100 \% I_{\mathrm{dc}}(606 \mathrm{~A})$ and curve 3 is under constant $50 \% I_{\mathrm{dc}}(303 \mathrm{~A})$. From Figure 6, it seems that the damage degree trend is affected by $I_{\mathrm{dc}}$ (or $I_{\text {rip }}$ in essence) seriously. The bigger $I_{\mathrm{dc}}$, the shorter the service life the capacitor possesses. With the damage degree threshold of 0.4 , the service life of CD137 capacitor under $100 \% I_{\mathrm{dc}}$, under varying $I_{\mathrm{dc}}$, and under $50 \% I_{\mathrm{dc}}$ is 15800,18900 , and 24800 hours, respectively.

Figure 7 shows the degrading process of CD137 capacitor under different $T_{\text {base }}$ while $I_{\mathrm{dc}}$ current stays $50 \%$ (303 A). Curve 1 in Figure 7 shows the degrading of capacitor with actual ambient temperature variation (illustrated by horizontal lines in Figure 7), while curve 2 in Figure 7 shows the (shown in Figure 6) process under constant $T_{\text {base }}$ of $90^{\circ} \mathrm{C}$ and curve 3 is under constant $55^{\circ} \mathrm{C}$. Similarly, the higher $T_{\text {base }}$, the shorter the service life the capacitor possesses. With a damage

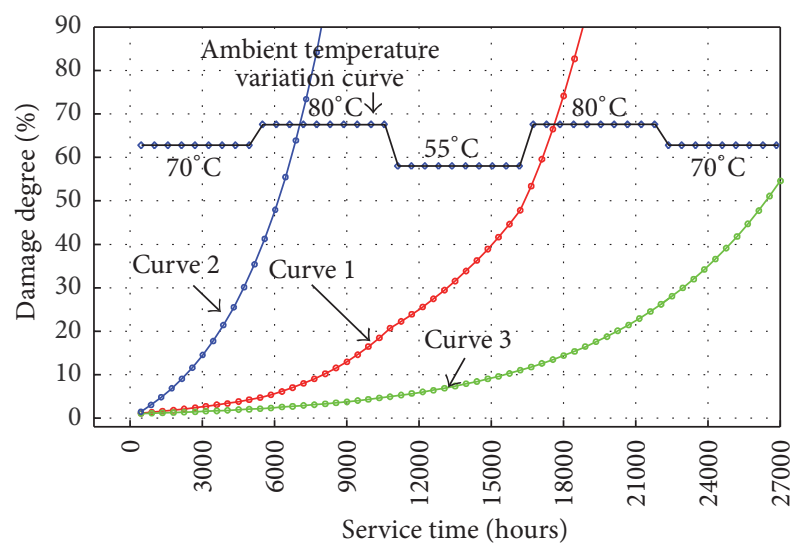

FIGURE 7: The aging of electrolytic capacitor with different ambient temperatures.

degree threshold of 0.4, the service life of CD137 capacitor under $90^{\circ} \mathrm{C}$, under varying ambient temperature, and under $55^{\circ} \mathrm{C}$ is 5300,15000 , and 24800 hours, respectively.

By comparison of Figure 7 with Figure 6, it shows that the affect from ambient temperature is more serious than that from DC load.

Figure 8 shows the comparison of prediction results with $\operatorname{GM}(2,1)$ model, with $\operatorname{GM}(1,1)$ model, and with the conventional model that is proposed in [9]. It seems that the prediction accuracy of all the three models is sufficient in steady states (in Figures $8(a)-8(c)$ ). However, the prediction errors with the three models are quite different in dynamic states, when $I_{\mathrm{dc}}$ or $T_{\text {base }}$ varies from time to time. In Figures $8(\mathrm{~d})$ and $8(\mathrm{e}), \mathrm{GM}(1,1)$ model obtains better prediction accuracy in the short-term range (up to around 6000 hours); however, its prediction error is unacceptable in the long term range (6000 hours to 27000 hours). Conventional model works excellently in time range up to 12000 hours but fails to play better than $\operatorname{GM}(2,1)$ model after that. For electrolytic capacitor, the most important time range of life prediction is 10000 to 30000 hours, and our proposed $\operatorname{GM}(2,1)$ model works with the least prediction error in such time range.

The prediction algorithm proposed in this paper is embedded directly into the control code of our existing 4QC, with no additional requirements for PCB board or sensors. So it is acceptable in the financial or maintaining point of view. With dSPACE, the authors set up a prediction prototype platform in the lab, to study the affect from such code addition, as is shown in Figure 9. A set of actual 4QC control boards are installed in the platform. The addition of our state evaluation and prediction code increases the execution time of the overall control code from $175 \mu$ s to $237 \mu$ s. Meanwhile, the control boards and the 4QC still work smoothly without any abnormal situations, which means that the execution increase of $58 \mu$ s does not affect the performance of existing $4 \mathrm{QC}$ control scheme and that the approach proposed is applicable and compatible with existing 4QC control code. 


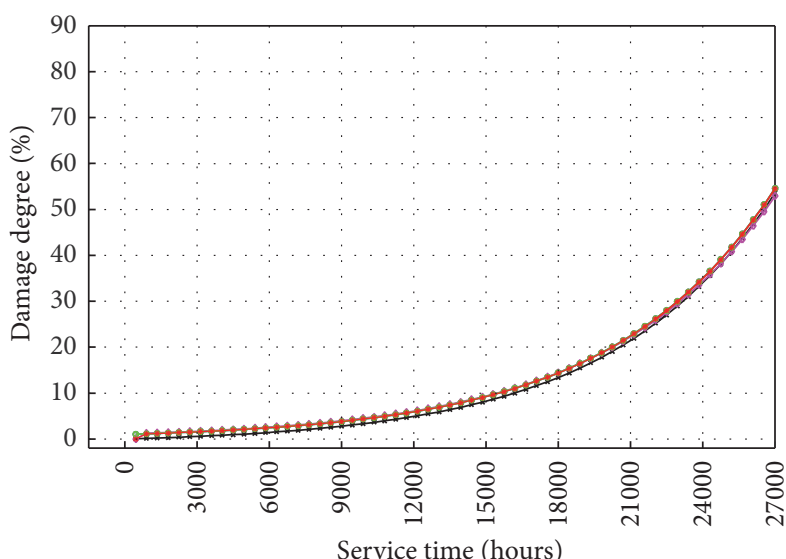

(a) The prediction result under $50 \% I_{\mathrm{dc}}$ and $T_{\text {base }}$ of $55^{\circ} \mathrm{C}$

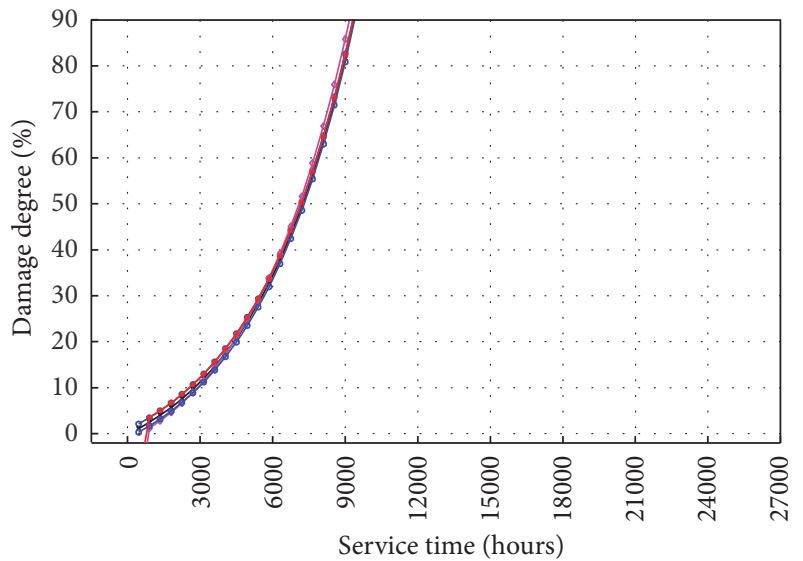

(c) The prediction result under $50 I_{\mathrm{dc}}$ and $T_{\text {base }}$ of $55^{\circ} \mathrm{C}$

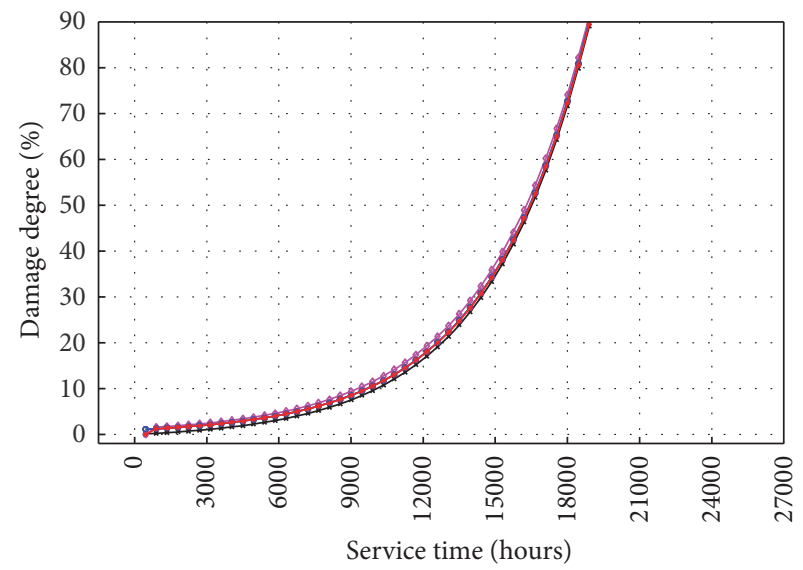

(b) The prediction result under $100 \% I_{\mathrm{dc}}$ and $T_{\text {base }}$ of $55^{\circ} \mathrm{C}$

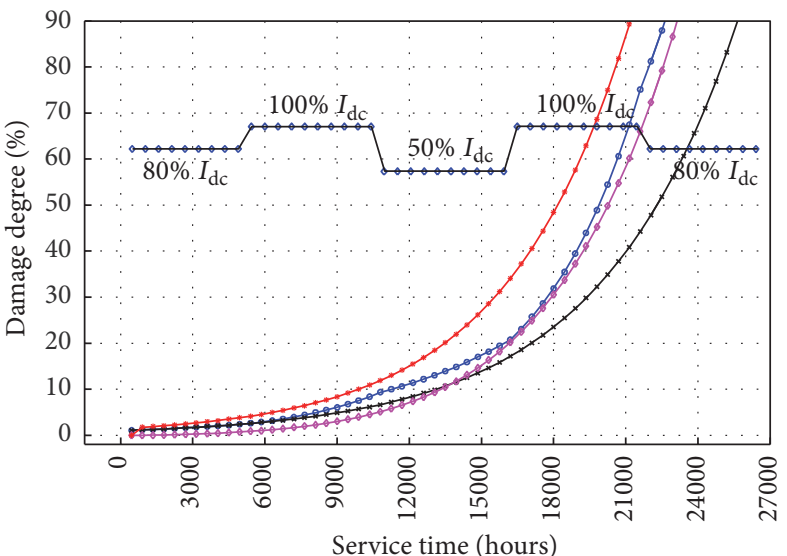

(d) The prediction result under varying $I_{\mathrm{dc}}$ and $T_{\text {base }}$ of $55^{\circ} \mathrm{C}$

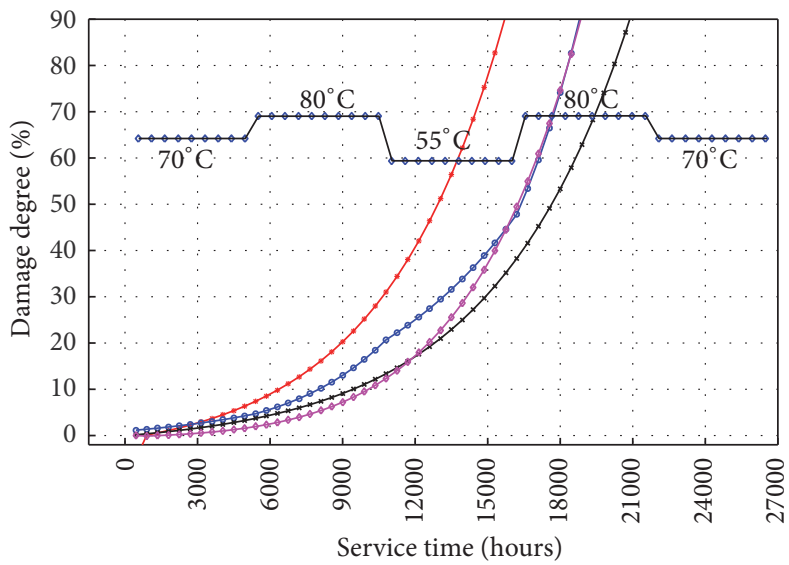

(e) The prediction result under varying $T_{\text {base }}$ and $50 \% I_{\mathrm{dc}}$

FIGURE 8: The service life prediction with $\operatorname{GM}(2,1)$ model, with $\operatorname{GM}(1,1)$ model, and with conventional model. - *-: prediction with GM(1, 1) model; -o-: actual damage degree along with service time; - $\diamond$-: prediction with $\mathrm{GM}(2,1)$ model; -- -: prediction with conventional model.

\section{Conclusions}

In power supply of urban transit system, electrolytic capacitors are relatively weaker among all the components of a 4QC. In order to ensure the reliability of the whole system, the state of capacitors must be evaluated online and the service life of them should be predicted. After that, measures could be taken in advance before capacitor failures. Conventional prediction approaches fail to work with sufficient accuracy under the varying DC load current and varying ambient temperature of a 4QC, while the proposed approach in this paper works better in such case. In our approach, iteration with electrical 


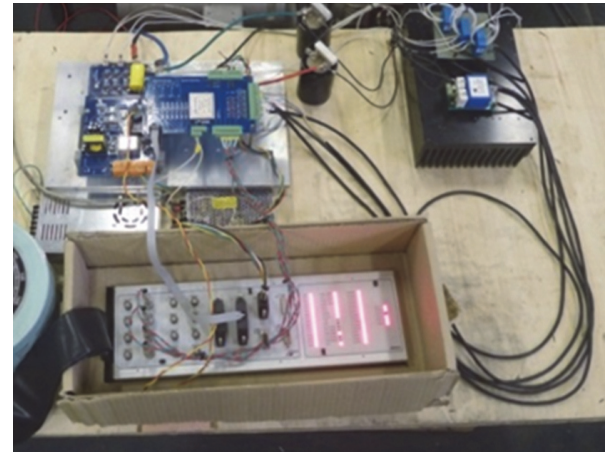

FIGURE 9: The dSPACE prototype platform for 4QC capacitor service life prediction.

quantities and $\operatorname{GM}(2,1)$ model makes it possible to obtain more accurate service life prediction with the existence of unpredictable load current and ambient temperature.

\section{Competing Interests}

The authors declare that there is no conflict of interests regarding the publication of this paper.

\section{Acknowledgments}

This work was supported by the Fundamental Research Funds for the Central Universities of China, no. E16JB00160/ 2016JBM062.

\section{References}

[1] W. Lei, L. Zhigang, Z. Gang, and S. Maosheng, "Research on a novel Traction Supply System for Urban Rail Transportation with 4-quadrant PWM converter," Power Electronics, vol. 7, pp. 75-77, 2009.

[2] L. Wang, G. Zhang, M. Shen, H. Quan, and Z. Liu, "A novel traction supply system for urban rail transportation with bidirectional power flow and based on PWM rectifier," in Proceedings of the International Conference on Energy and Environment Technology (ICEET '09), pp. 40-43, October 2009.

[3] K. Harada, A. Katsuki, and M. Fujiwara, "Use of ESR for deterioration diagnosis of electrolytic capacitor," IEEE Transactions on Power Electronics, vol. 8, no. 4, pp. 355-361, 1993.

[4] P. Venet, F. Perisse, M. H. El-Husseini, and G. Rojat, "Realization of a smart electrolytic capacitor circuit," IEEE Industry Applications Magazine, vol. 8, no. 1, pp. 16-20, 2002.

[5] A. M. Imam, D. M. Divan, R. G. Harley, and T. G. Habetler, "Real-time condition monitoring of the electrolytic capacitors for power electronics applications," in APEC 2007-22nd Annual IEEE Applied Power Electronics Conference and Exposition, pp. 1057-1061, usa, March 2007.

[6] A. M. Imam, T. G. Habetler, R. G. Harley, and D. Divan, "Failure prediction of electrolytic capacitor using DSP methods," in Proceedings of the 20th Annual IEEE Applied Power Electronics Conference and Exposition (APEC '05), vol. 2, pp. 965-970, IEEE, Austin, Tex, USA, March 2005.
[7] S. Asgarpoor and M. J. Mathine, "Reliability evaluation of distribution systems with non-exponential down times," IEEE Transactions on Power Systems, vol. 12, no. 2, pp. 579-584, 1997.

[8] H. Soliman, H. Wang, B. Gadalla, and F. Blaabjerg, "Condition monitoring for DC-link capacitors based on artificial neural network algorithm," in Proceedings of the 5th IEEE International Conference on Power Engineering, Energy and Electrical Drives (POWERENG '15), pp. 587-591, May 2015.

[9] M. L. Gasperi, "Life prediction model for aluminum electrolytic capacitors," in Proceedings of the Industry Applications Conference, pp. 1347-1351, October 1996.

[10] Y.-M. Chen, H.-C. Wu, M.-W. Chou, and K.-Y. Lee, "Online failure prediction of the electrolytic capacitor for LC filter of switching-mode power converters," IEEE Transactions on Industrial Electronics, vol. 55, no. 1, pp. 400-406, 2008.

[11] M. Hao and L. Wang, "Fault diagnosis and failure prediction of aluminum electrolytic capacitors in power electronic converters," in Proceedings of the 31st Annual Conference of IEEE Industrial Electronics Society (IECON '05), pp. 842-847, Raleigh, NC, USA, November 2005.

[12] K.-W. Lee, M. Kim, J. Yoon, S. B. Lee, and J.-Y. Yoo, "Condition monitoring of DC-link electrolytic capacitors in adjustablespeed drives," IEEE Transactions on Industry Applications, vol. 44, no. 5, pp. 1606-1613, 2008.

[13] A. M. R. Amaral and A. J. M. Cardoso, "A simple offline technique for evaluating the condition of aluminum-electrolyticcapacitors," IEEE Transactions on Industrial Electronics, vol. 56, no. 8, pp. 3230-3237, 2009.

[14] A. M. R. Amaral and A. J. Marques Cardoso, "Simple experimental techniques to characterize capacitors in a wide range of frequencies and temperatures," IEEE Transactions on Instrumentation and Measurement, vol. 59, no. 5, pp. 1258-1267, 2010.

[15] H. Soliman, H. Wang, B. Gadalla, and F. Blaabjerg, "Condition monitoring for DC-link capacitors based on artificial neural network algorithm," in Proceedings of the 5th IEEE International Conference on Power Engineering, Energy and Electrical Drives (POWERENG '15), pp. 587-591, IEEE, Riga, Latvia, May 2015.

[16] T. Kamel, Y. Biletskiy, and L. Chang, "Capacitor aging detection for the DC filters in the power electronic converters using ANFIS algorithm," in Proceedings of the IEEE Canadian Conference on Electrical and Computer Engineering (CCECE '15), pp. 663-668, May 2015.

[17] A. Wechsler, B. C. Mecrow, D. J. Atkinson, J. W. Bennett, and M. Benarous, "Condition monitoring of DC-link capacitors in aerospace drives," IEEE Transactions on Industry Applications, vol. 48, no. 6, pp. 1866-1874, 2012.

[18] Y. Yu, T. Zhou, M. Zhu, and D. Xu, "Fault diagnosis and life prediction of DC-link aluminum electrolytic capacitors used in three-phase AC/DC/AC converters," in Proceedings of the 2012 2nd International Conference on Instrumentation and Measurement, Computer, Communication and Control (IMCCC '12), pp. 825-830, Heilongjiang, China, December 2012.

[19] X. Lu, Z. Liu, L. Wang, and H. Quan, "Estimate approach for fatigue damage of aluminum electrolytic capacitor based on accumulated damage theory," Transactions of China Electrotechnical Society, vol. 26, no. 4, pp. 13-18, 2011.

[20] R. Jiang and T. Wang, "Log-weibull distribution as a lifetime distribution," in Proceedings of the International Conference on Quality, Reliability, Risk, Maintenance, and Safety Engineering (QR2MSE '13), pp. 813-816, IEEE, Chengdu, China, July 2013. 
[21] X.-H. Zhu, S.-M. Cui, N. Shi, and Y.-L. Min, "Grey prediction model of motor reliability of electric vehicle," Electric Machines and Control, vol. 16, no. 8, pp. 42-46, 2012.

[22] F. Gao and T.-J. Yan, "Vibration state forecast for electrical submersible pump unit based on dynamic gray model," in Proceedings of the International Conference on Mechanic Automation and Control Engineering (MACE '10), pp. 6224-6227, June 2010.

[23] L. Juan, X. Zhang, X. Chen, and N. F. Mohammed, "Sensor fault diagnosis study of UUV based on the grey forecast model," in Proceedings of the 12th IEEE International Conference on Mechatronics and Automation (ICMA '15), pp. 1750-1754, Beijing, China, August 2015.

[24] Y. Lingbin, Z. Xia, and W. Jin, "Prediction of the number of international tourists in China based on gray model $(1,1)$," in Proceedings of the 2009 International Conference on Electronic Commerce and Business Intelligence (ECBI '09), pp. 357-360, Beijing, China, June 2009.

[25] R.-R. Zheng, J.-Y. Zhao, and T.-T. Zhao, "Prediction of power transformer oil dissolved gas concentration based on modified gray model," in Proceedings of the International Conference on Electrical and Control Engineering (ICECE '10), pp. 1499-1502, IEEE, Wuhan, China, June 2010.

[26] J. Yin, C. Gao, and X. Jia, "Wavelet packet analysis and gray model for feature extraction of hyperspectral data," IEEE Geoscience and Remote Sensing Letters, vol. 10, no. 4, pp. 682-686, 2013.

[27] CD137 capacitor dada sheet. Provided by Nantong Jianghai Capacitor Co., Ltd, 2010. 


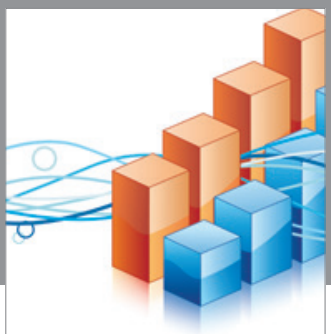

Advances in

Operations Research

vatem alat4

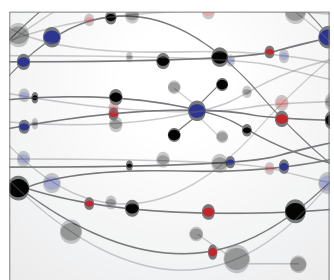

\section{The Scientific} World Journal
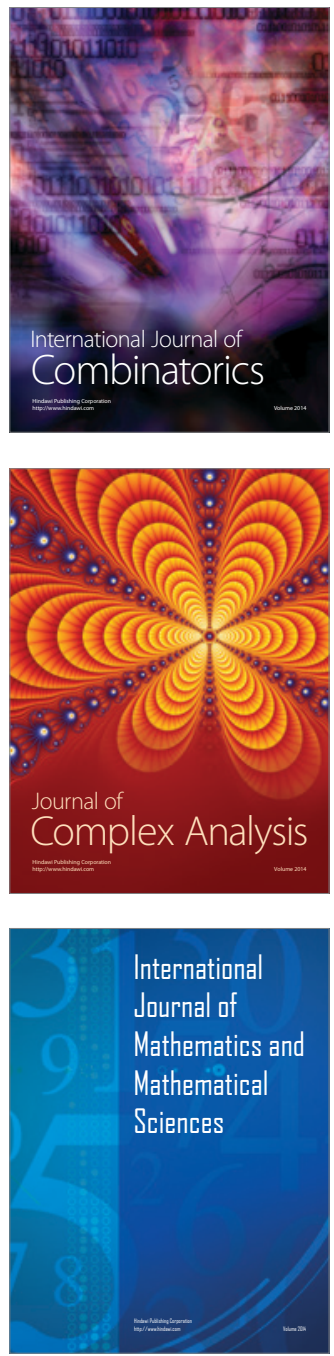
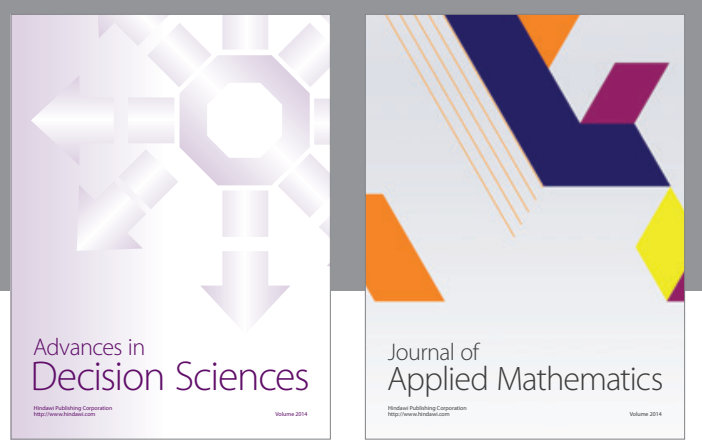

Algebra

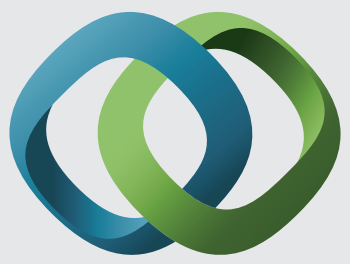

\section{Hindawi}

Submit your manuscripts at

https://www.hindawi.com
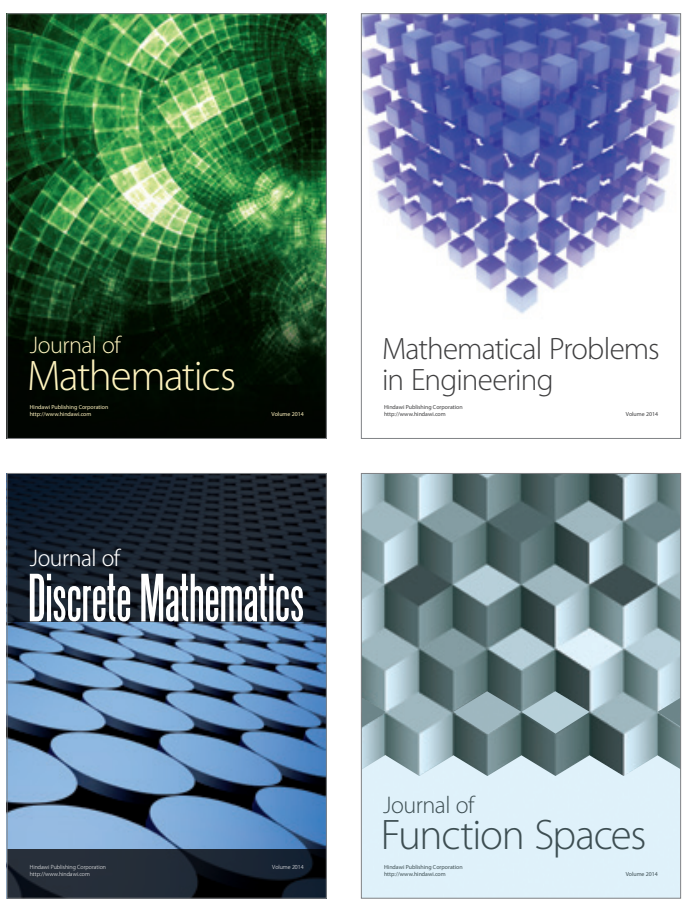

Mathematical Problems in Engineering
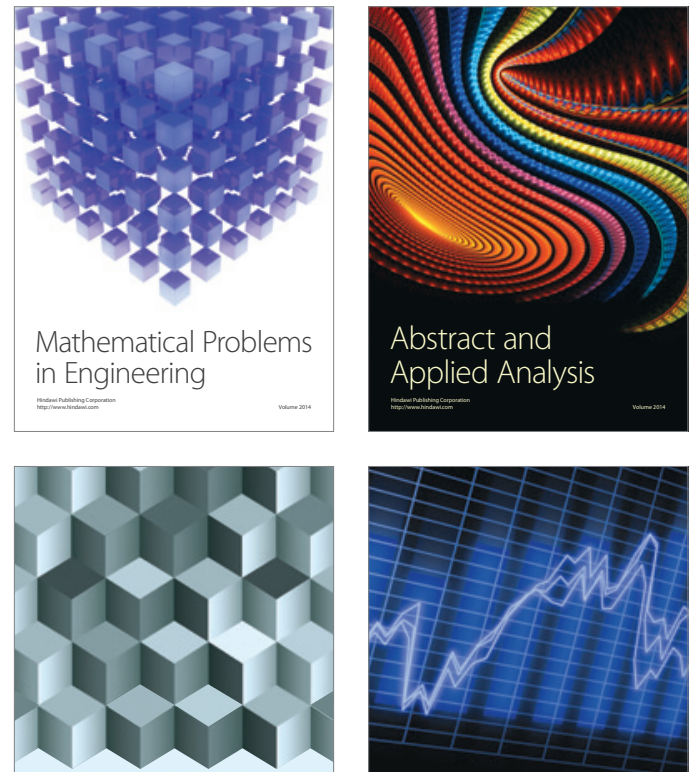

Journal of

Function Spaces

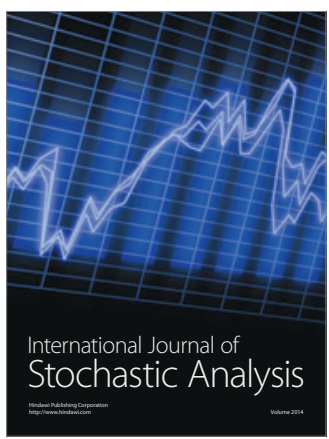

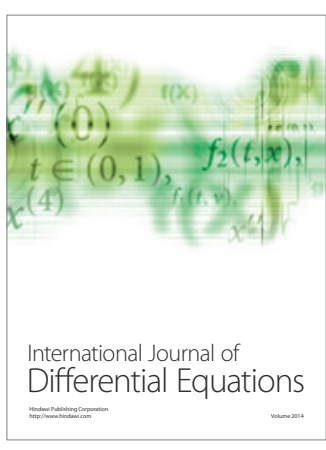
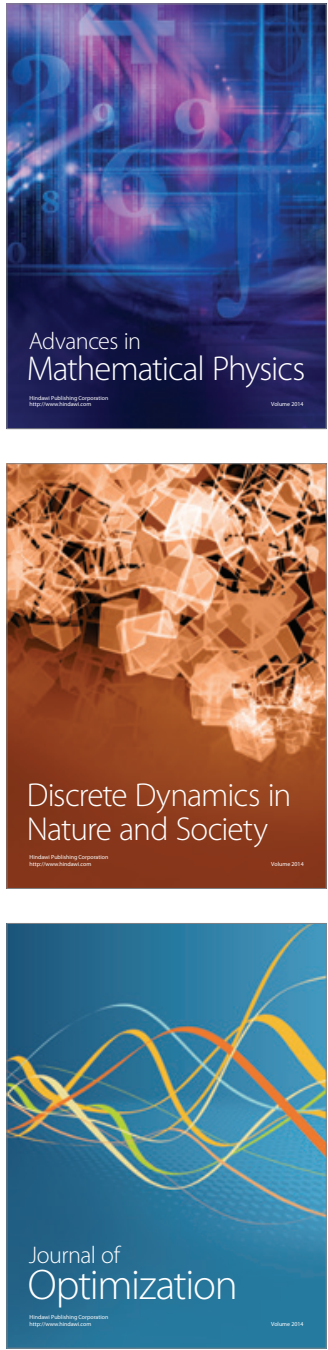